\title{
A Web-Based Tool for Collaboration and Transdisciplinary Learning Design in Communities of Practice
}

\author{
http://dx.doi.org/10.3991/ijac.v9i2.6014 \\ Vestergaard, Erik ${ }^{1}$, Storm, Helle ${ }^{2}$ and Hansen, Gitte Riis ${ }^{1}$ \\ ${ }^{1}$ University College Zealand, Roskilde, Denmark \\ ${ }^{2}$ University College Zealand, Sorø, Denmark
}

\begin{abstract}
-idématch is a digital, web-based, and noncommercial platform developed by associate professors from University College Zealand, in cooperation with private enterprises, municipalities, and students. It is designed to bring students, public and private organizations, and citizens together, transforming ideas into practical solutions, through innovation, using collaborative and transdisciplinary learning designs contributing to new ways of welfare solutions for the Region of Zealand. The key focus is the contribution to innovation in partnership with the work field, students' learning processes, and the development of analytical, experiential, experimental, and management competencies.
\end{abstract}

Index Terms - collaborative, innovation, learning design, transdisciplinary.

\section{INTRODUCTION}

idématch has been designed and developed by associate professors from different programs - Social Education Program, Nutrition and Health Program, Management and researchers from the Research and Development Department at University College Zealand (UCZ) in cooperation with two private enterprises. Thus, idématch has been developed in a transdisciplinary setting as a public/private innovation.

A strong focus on innovation as the key competencies in the knowledge society characterizes education as such and professional education, specifically. According to Ronald Barnett [1], education is aiming at "an unpredictable future," which is characterized by hyper complexity, and provides innovative competences as skills and as a way of being a professional. In a broad sense, the unpredictable future and the contingency of time calls for possession and the development of changing skills and serendipity [2] [3]. In that perspective, the professional educators are obliged to focus on innovation, related to mode 1 [4] and on the development of the students' innovative competences, related to mode 2 [4] according to the executive order.

The Professional Bachelor Programs aim to educate professional experts who can develop their own work as members of a work community by finding new solutions to welfare issues, in order to contribute to the overall societal innovation capacity.

Specifically, idématch is a digital platform in which it is possible to produce and disseminate ideas and concepts developed in close cooperation among education (students and lecturers), work field partners, communities, local authorities, and others for the benefit of the region's overall development. idématch contributes to innovation in partnership with the work field, communities, and commercial actors. As part of education that is more professionally oriented, as part of working with education design that is linked to real life work field, and as part of a strong focus on the students' development of competences, a need for a tool that could specifically link the educational institution and the world outside has been emerging in recent years. idématch addresses this need.

However, this paper examines and points out the underlying educational and learning foundation and implications of idématch. In this perspective, the intension is to acknowledge idématch as a tool that can actually support education that is aiming at learning environments where students develop innovative competence, and learning environments that are scaffolding learning processes, which are situated, interactive, and social in closely cooperating with the work field. idématch is a tool that emphasizes acting together on projects that are connected to real life situations and challenges. Thus, it is the overall educational aim that the students truly have the possibility to become development-oriented professional experts of their work field and contribute to a welfare task.

\section{The Design AND UsE Of IdÉmATCH}

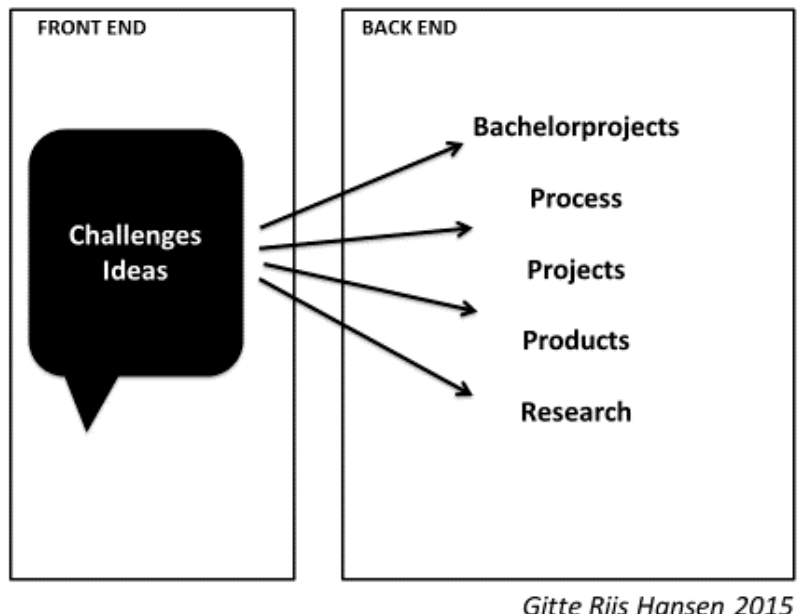

Figure 1. Front End and Back End in idématch. 
idématch [5] is a non-commercial digital platform enhancing the cooperation and collaboration between education and various actors from "the world outside"; work fields, public organizations, communities, businesses, citizens, other educations and more. In the Front End, representatives from the work field, communities or students, researchers, and teachers are able to upload and describe ideas or challenges of any kind that they are facing. These challenges and ideas are linked to students, teachers or researchers, communities, work fields, or others and become projects or didactic tools for use in teaching.

In Front End, ideas and challenges mature by comments and followers until a match has taken place and a team elects a project. The projects can be designed as several kinds of projects as shown in the figure above. As soon as a challenge or an idea has become a project, the project continues into "Back End". In Back End, the project is no longer available for matching. Back End offers a kind of working space that offers tools such as templates for working with projects, creating project designs, and tools for cooperation and communication. Thus, besides the maturing and matching of challenges and ideas, idématch offers a concrete online digital space for working systematically, collaboratively, and cooperatively with the project as soon as a match has taken place. Accordingly, idématch supports the possibility for the participants to develop innovative project skills and competencies. "Idea Guides" - lecturers that guide and facilitate the processes, facilitate processes in Front End and in Back End.

\section{EDUCATIONAL AND LEARNING FOUNDATIONS AND INDICATIONS}

In UCZ, the educational and learning perspective has, within the past few years, changed from a teaching perspective to a learning perspective. The organizational and structural educational framework is focused and directed towards increased professional competences, founded on research - based knowledge, knowledge in practice, of practice and for practice, and directed towards the developing of innovative competences. The professional bachelor programs, in general, provide "teaching methods that can develop the students' independence, collaborative skills, and innovative skills" [6] that qualifies the students to independently analyze, evaluate, and reflect on problems in order to carry out practices - based, complex, and development-oriented job functions in the work field. Their exchange programs based on a combination of theoretical education and training internship characterize the education. Laurillard describes this as "The tension between students' development of specialized codified knowledge and development of broader generic skills that the work field demands" [7]. This tension underlines that the education must provide the integration of different types of knowledge: theoretical knowledge and experiential knowledge that - embedded in skills - are transformed into the development of competences. Furthermore, there is a strong focus on research - based knowledge in the professional bachelor programs that point at an education and learning perspectives that reconcile research, learning and regional development [8].

Based on the education policy and the structural educational frameworks, the professional education programs need to be in closer contact with the working field, which the education is directed against. idématch is a concrete tool that supports this contact and contributes in this way to 'bridging the gap' between theoretical and practical knowledge.

idématch is an embodiment of a way of thinking and understanding education and learning processes. That indicates a teaching design and learning perspective based on principles, as will be elucidated hereinafter.

\section{ACtion-Oriented And Practice -BASED LEARNING.}

The intension of idématch is that students acquire competences by engaging with issues and challenges encountered in 'real life' work fields. Thus, idématch supports an action-oriented approach to learning that links "study and life". According to Dewey [9], learning takes place most favorably through models and applications that have genuine foundations in life. The pragmatic view that Dewey [10] represents emphasizes that theory and practice are intertwined; knowledge is built through interaction between action and thinking. The assumption is that the sources of theory lie in the practical world carried by experience. idématch enhances this assumption because all projects that emerge from idématch are defined by challenges from existing practices. This action-oriented approach aims to solve current practical problems while expanding scientific knowledge. The point is, according to Dewey [9], that competencies must be learned by experiences. idématch contributes to a qualification of experiences because it is embedded in a didactic framework governed by the defined competencies.

In a work field perspective, the involvement of students and lecturers offers the possibility to improve the quality of problem solving and rates of innovation because the challenges undergo a systematically facilitated investigation. Furthermore, idématch addresses the work field interest in fostering high-level generic knowledge skills.

\section{InNOVATIOn, COllaborative LEARNing, AND COMMUNITIES OF PRACTICE}

idématch a tool for enhancing collaborative learning and knowledge production in learning processes. It consists of reconstructing and building experiences. It is a tool that supports collaborative cooperation in which participants work together in solving a challenge [11]. Participants in these collaborative learning scenarios will essentially have the "same knowledge" because they undergo the same processes. Thus, working with idématch requires the creation of a learning community in which the task can be solved. With idématch, answers and solutions are systematically co-created for problems, challenges, and new opportunities in which new competencies are required. Learning has a clear mutually defined objective (between students, lecturers, and work field partners and citizens) and takes place through the process of abductive knowledge creation.

The table below (Fig. 2) is an elaboration of a model originally designed by Knud Illeris [11]. The table describes the dimensions proceeding idematch; it includes learning connections, learning processes, and contexts. One process is the interaction between the individual and the social and material environment, which always takes place and to which we can give more or less attention. "The criteria for this process is of a historical, geograph - 


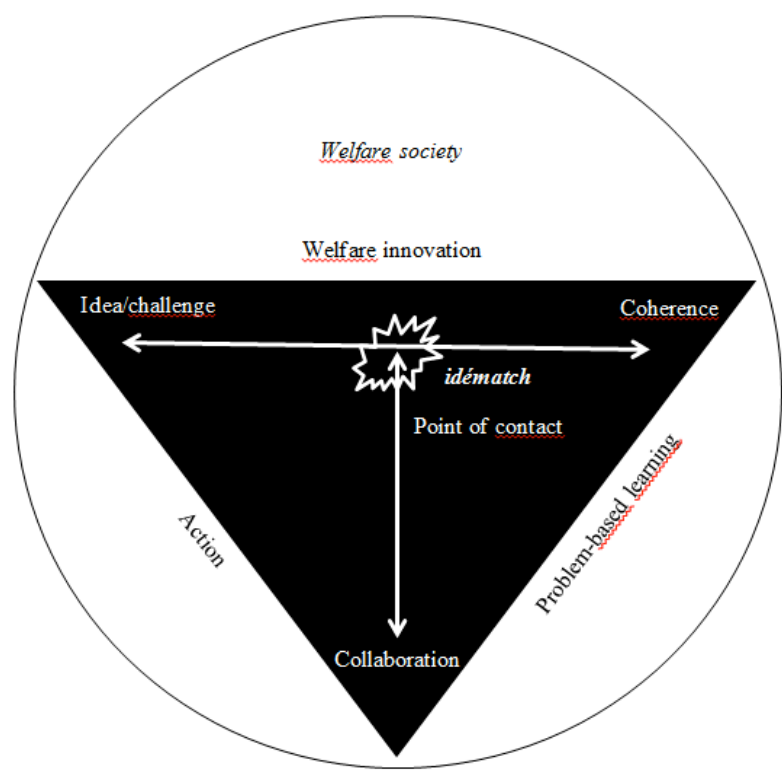

Figure 2. Learning framework in relation to idématch

ical, and social nature: it basically depends on the time and place" [11]. idematch is focused upon both the individual and the social learning process. We use 'context' as an expression of the coherence that the members individually and collectively attribute to the subject as an important prerequisite for instructive and durable learning outcomes of the process.

The challenges and ideas we refer to in Figure 2 are the issues and content for the participants' learning. Learning processes always involves three different elements: the content/issue, the learning driving force, such as psychic energy, that mobilizes, and the social communities.

The figure prescribes a "condensed" learning environment, not only for students, but for all participants. idématch positions itself as a "point of contact" between cooperation and coherence in relation to the focus in the different tasks (challenge/idea).

The "welfare society" is a kind of backdrop that frames idématch. The results of cooperation in idématch contribute to the development of the public welfare services in a continuing loop process.

This innovative learning design tends not only to give the students the possibility to develop innovative competences, where analytical, experiential, and experimental competencies are essential, but also to provide partnerships for a strong integration of innovation strategies and research, primarily regionally located with the possibility of being of practical relevance.

\section{PROBLEM-BASEd LEARNING}

Participating in learning processes of idématch is grounded in problem-based learning. In that perspective, problem-based learning emerges in the field between coherence and cooperation in relation to the task. The problem-based learning process is based on students acting, researching, and reflection based upon recognition in work field situations. Learning in idématch is based on authentic problems and is characterized by participants independently managing and organizing the process. Thus the learning processes are often experienced as intense and demanding, but at the same time many participants experience that the problem-based learning process provides energy, and is academically interesting, meaningful, and relevant.

Problem-based learning is focused on the learning process of the work field partners and for the student - the learning process and outcome are not based on a predetermined curriculum. It emphasizes the learning issue as a joint learning process and problem solving process. The students are perspective researchers as well as facilitators.

\section{SOCIETAL AND TRANSDISCIPLINARY TEACHING AND KNOWLEDGE DisTRIBUTION}

In "My Pedagogic Creed", Dewey claims that "Education [is] a social process [...]".[13] Besides experience, Dewey emphasizes the importance of social relations and interaction, which underlines the point of the pragmatic learning perspective that learning is social and knowledge is socially distributed. According to idématch, knowledge is distributed in two overall ways:

1. Knowledge is developed and shared in a social context. Learning in this sense is characterized by the knowledge learned in the situations in which they are carried out. The point is that participation in the real life situation creates learning and identity [14]. idématch is a tool that to some extent gives access to this kind of learning process.

2. Knowledge is shared and developed on a digital platform that is open to everyone who signs in. idématch offers knowledge about what are the current and relevant challenges and topics, what kind of knowledge is produced in working with the challenges, and what academic and professional issues preoccupy students and researchers.

According to Dewey, education is "to prepare [...] for the future life [...]" [13]. The future life to prepare for is in this context the work life as a professional. By participating in cooperation with the work field and societal stakeholders and by developing competencies by working with real life challenges, the participating students get the ability to learn the "regime of competence" [and] set of criteria and expectations" [14] that characterize the work field and the understanding of "a professional". Learning is not just acquiring knowledge and skills; learning in education is also becoming a professional with an identity as a professional in a certain professional context.

In addition to a tool for societal learning, idématch is a tool for transdisciplinary learning, focused on contextual understanding and interactive research methods. Transdisciplinary learning is related to Mode 2 [4] and is characterized by distinct parameters that are summed up as the following: Knowledge production is context-oriented, problem-focused, and transdisciplinary. The problems and challenges derive from "practice" and are assessed in relation to application areas and learning.

idématch is a platform where challenges can "sign in" from different educational entities and from different work fields, communities, or businesses and be matched, and vice versa. In this way, different disciplines have the opportunity to offer engagement and cooperation crosswise.

One of the purposes of idematch is that students will perform bachelor projects trans-disciplinarily. Besides the students acquiring interdisciplinary skills, they also learn to understand professions as inter-disciplinarily founded - 
the professional work is carried by trans-discipline and an action component. The solution to some of the tasks is developed as a trans-disciplinary design where different kinds of students and employees work together and involve citizens in solutions that concern themselves.

Furthermore, the transdisciplinary aspect provides the generation of new competencies and innovation for all participants. The transdisciplinary problem solving provides the different skills and knowledge of the participants to be integrated within the framework of the activity and thus creates new perspectives on the subject, new skills, and new competencies.

When the different participants work together in idématch to solve a challenge and on developing the issue and challenges, they not only produce knowledge, skills, and professional competence related to the issue in focus and the professional solution. At the same time, they develop relational competence, which is important for the cooperation that makes them able to achieve the goals and create sustainable solutions as professionals.

\section{NETWORK AND NETWORKED LEARNING}

Last but not least, the significance of networking and networked learning is to be considered. Networking plays a crucial role in at least two aspects when regarding idématch as a learning and educational tool:

1. Networked learning is regarded as "[...] connections with people and information and communication in such a way so as to support one another's learning [...]" [15]. idématch is a tool for "matching", for connecting. Peter Goodyear claims that successful networked learning for one thing depends on "designing good learning tasks, ensuring good access to robust and appropriate technology [...]" [16]. Good learning tasks are in the perspective of this paper, real life challenges, which are considered as the basic idea of idématch. The platform is designed to be supportive to exactly this foundation.

2. Cooperation with partners from the work field offers the opportunity for the students and the work field partners "to get to know each other" before they become professional colleagues. In other words, the cooperation between students and work field partners can be used not only concerning the process of recruiting or the identification of talents. The close cooperation creates opportunities to develop social capital that can be defined as the characteristic that enables members to jointly solve the core task (the challenge). In order to solve their core tasks, it is necessary that participants master collaboration based on a high level of trust and justice [17].

Through the infrastructure of the web-based portal, idématch offers the structure to collaborate. Collaboration is in many ways a cognitive and structural element that helps the participant of an organization to succeed. The cognitive component of social capital will, in this sense, be how the participants think of and define the core task, which is the aim of the corporation. This perspective emphases that idématch can be defined as development of social capital and the interaction among different participants in the collaboration process, and is based upon shared knowledge, shared goals, and mutual respect. [18].

\section{Considerations On Teaching Design And ROLES OF THE PARTICIPATING ACTORS}

idématch as a tool has an impact on teaching design and implementation. It as a tool that indicates a teaching design and learning perspective that enhance innovation and development as an integrated part of learning. The point is that learning is vocationally directed and therefor every learning situation should aim to increase the development of the students' practical and professional competencies. In this perspective, there are significant similarities between Learning by Developing - as developed and described by Laurea University of Applied Sciences [19] and idématch. Thus, idématch demands an educational structure where developing goes hand in hand with the didactic management of the requirements of the Ministerial Order and the structural administration of the education as such. In addition to the above mentioned similarities, idématch offers materials and teaching elements for teaching designs that are enhancing e.g. flipped learning and collaborative learning methods - it is a platform full of real life cases that are to be brought into the "classroom".

The fundamental idea and learning concept that idématch implicates tends to provide a change in understanding the roles of the participants: the students, the lecturers, and the works field partners. The learning perspectives implicates an equality among students, lecturers, and work field partners aiming at co-creation and co-developing, which calls for another way of understanding the roles of the participants. Teaching as distributing knowledge and information like traditional lecturing is inadequate in the learning and teaching perspective attached to idématch. Students are genuinely being placed in the core of all learning activities - focus is on the students' learning processes - not the lecturers' teaching. The role of "the teacher as the expert" takes a turn from the "teacher is the one that knows" to the teacher as learning and knowledge guide and as facilitator of learning and innovative processes.

Moreover, the main task for the lecturer is changing because the lecturer is expected to participate in work field development and development of the region as well as teaching. Teaching turns into a student-centered learning environment for knowledge, skills, values, and experiences. Taatila [20] points out five teacher roles that evolve when teaching is student-centered, action - and competence oriented, based on collaboration and cooperation: motivator, challenger, process consultant, information source, and evaluator. The lecturer gets a new set of colleagues who will be experts as themselves - in other disciplines. idématch calls for student centered activities that requires each student to become an active member of a social team whose task it is to develop and share knowledge. idématch gives the student an opportunity to work with and learn from real life situations and challenges in cooperation with the future professional working field, an opportunity that will provide a reduction of the theoretical and practical gap. In an educational teaching design that is based on action- oriented, innovative processes with real life challenges, learning is situated in a quite open environment characterized by relatively high complexity and uncertainty.

As for work field partners, the role will change because they will play a much more active role in education of professionals. This will change the "daily life" in the work 
field and will require other priorities and competencies of professionals and the organizational structures. Thus, idématch gives both learning opportunities for the individuals learning in communities of practice and the development of a relational competence.

\section{PERSPECTIVES}

idématch. $d k$ as a digital tool for innovative, social, and transdisciplinary learning designs faces a least four challenges:

1. idématch is based on the idea of learning by experience [9]. It raises the question of whether the acquired experiences are educationally adequate and relevant. Though idématch contributes to a qualification of experiences because idématch is embedded in a didactic framework, there is the concern about whether the students get the possibilities to develop the competencies that are actually required according to the executive order. That is a challenge for all participants and provides capacity to have a strong focus on project planning, didactic designing, and facilitating processes.

2. The change of teaching design that is based on action-oriented, innovative processes with real life challenge learning is situated in a quite open environment characterized by relatively high complexity and uncertainty. This uncertainty applies for all participants but mostly for students because they have an education at stake: They are obligated to pass exams and tests that are related to the executive order. For both students and lecturers the urge to be in control with the learning process is challenged.

3. The integration of work field and private enterprises is the core of learning design that is action-based and based on experience and cooperation. The work fields are being engaged strongly in the education of professionals. For some work field partners this is a task they will welcome and be engaged in. But nevertheless it will be another task to fulfill. For (especially) public work field partners this is a challenge often reasoned by lack of resources. In this perspective, learning is a phenomenon that is situated in a cultural, economic, and social context. The students are therefore dependent not only on their own drive, but also on the context and social capital in which learning occurs.

4. idématch is a digital tool and therefore it requires digital competencies to be a participant and to get the full educational advantage. It requires competencies according to digital cooperation between students and lecturers and the work field partners.

Thus, idématch empowers educational collaboration across theoretical and practical fields. Though idématch addresses an educational request in political, educational, and societal perspectives, the acknowledgement and implementation need attention and new initiatives as an educationally integrated initiative.

\section{ACKNOWLEDGMENT}

idématch is based on the effort and co-operation from students, work fields partners, and other users and we would like to express our gratitude to the participants for their interest and encouragement.

\section{REFERENCES}

[1] Barnett, R. (2004). Learning for an unknown future. Higher education Research \& development, 23 (3), pp. $247 \quad-260$. http://dx.doi.org/10.1080/0729436042000235382

[2] Kirkeby, O. F. (2013). Eventologien. Frederiksberg: Forlaget Samfundslitteratur.

[3] Holm, S. B. and Hansen, G. R (2014). Utopi og dannelse - dannelse i et eksistentielt perspektiv. I: Psyke \& Logos, 2014, 35, 229245

[4] Gibbons M., Limoges, C., Norwotny, H., Schwartzman, S., Scott, P., Throw, M. (1994). The new production of knowledge. The dynamics of science and research in contemporary societies. London: SAGE

[5] http://www.idematch.dk

[6] Ministry of Higher Education and Science: http://ufm.dk/en/ legislation/prevailing-laws-and-regulations/education/files/ministe rial-order-on-academy-profession-programmes-and-professional161213.pdf

[7] Laurillard, D. (2012): Teaching as a Design Science. Routledge. pp 24

[8] Frascati Manual 2002.

[9] Dewey, J. (1963): Experience and Education. New York: Collier Books.

[10] Dewey, J. (1929). The quest for Certainty; A study of the relation of knowledge in action. New York: Minton, Balch and Company.

[11] Lave, J. \& Wenger, E (1991) Situated Learning: Legitimate peripheral participation. Cambridge: Cambridge University Press. http://dx.doi.org/10.1017/CBO9780511815355

[12] Illeris, Knud (editor) (2009): Contemporary Theories of Learning. Learning theorists ... in their own words. Routledge.

[13] Dewey, J. (1897). My Pedagogic Creed. School Journal vol 54, pp $77-80$.

[14] Wenger, E. (1999). Communities of Practice: Learning, Meaning and Identity. Cambridge University Press.

[15] Dirckinck-Holmfeld, L., Jones, C., and Lindström, B. (2009). Analyzing Networked Learning Practices in Higher Education and Continuing Professional Development. Sense Publishers. Rotterdam/Boston/Taipei.

[16] Goodyear, P. (2005). Educational design and networked learning: Patterns, pattern languages and design practice. Australian Journal of Educational Technology. 2005, 21(1), 82 -101. http://dx.doi.org/10.14742/ajet.1344

[17] Olesen, Kristian Gylling et al (2008): Virksomhedens sociale kapital. Hvidbog. Arbejdsmiljørådet.

[18] Gittell, Jody Hoffer (2012); Effektivitet $i$ sundhedsvaesenet. Munksgaard.

[19] Raij, K. (2007). Learning by Developing.Laurea Publications A 58.

[20] Taatila, V. (2014). Some experience -based considerations on the LbD Action Model: In: Katariina Raij (ed): Learning by Developing action model. Laurea Publications.

\section{AUTHORS}

Erik Vestergaard is assistant professor at Center for Management and Experience and Design, University College Zealand, Denmark (E-mail: erve@ucsj.dk).

Helle Storm is associate professor at Center for Nutrition and Rehabilitation, University College Zealand, (email: hst@ucsj.dk).

Gitte Riis Hansen is associate professor at Center for Social Education, University College Zealand, Denmark (e-mail: grh@ucsj.dk).

This article is an extended and modified version of a paper presented at the the International Conference on E-learning in the Workplace 2016 (ICELW 2016), held in June 2016, at Columbia University in New York, NY, USA. Submitted 14. March 2016. Published as resubmitted by the authors 27 April 2016. 